Journal of Advanced Research in Fluid Mechanics and Thermal Sciences

Journal homepage: www.akademiabaru.com/arfmts.html ISSN: 2289-7879

\title{
Numerical and Experimental Modelling of Small Hydropower Turbine
}

\author{
Omar Sulaiman Abdullah ${ }^{1}$, Ammar Hatem Kamel ${ }^{1,}{ }^{*}$, Wissam Hashim Khalil ${ }^{2}$ \\ Dams \& Water Resources Engineering Department, Engineering College, University of Anbar, Ramadi, Iraq \\ Renewable Energy Research Center, University of Anbar, Ramadi, Iraq
}

\section{ABSTRACT}

Article history:

Received 11 September 2020

Received in revised form 18 November 2020

Accepted 22 November 2020

Available online 4 February 2021

Keywords:

screw turbine; small hydropower station;

low head turbine; CFD; physical model

\begin{abstract}
Recently, Archimedes screw turbines have been developed to operate as small hydropower stations, because of its reliability to operate with the low head (less than $5 \mathrm{~m}$ ) and its low cost of design and operation. In the present study, the influence of the flow rate, shaft inclination angle, and the number of blades is studied using physical and numerical model to determine the performance of Archimedes screw turbine at Ramadi Barrages in Iraq. The physical model was made of stainless steel with the following parameters: (the radius ratio is 0.536 , the pitch is $70 \mathrm{~mm}$, the shaft angles are $30^{\circ}, 35^{\circ}, 40^{\circ}, 45^{\circ}$ ). The experimental work on the physical model is achieved with different flow rates and angles. The results showing that the highest efficiency is 81.4 $\%$ at the angle of $35^{\circ}$ and the flow rate is $1.12 \mathrm{l} / \mathrm{s}$. The maximum energy obtained is $25.13 \mathrm{w}$ at the angle of $45^{\circ}$, the flow rate is $2.065 \mathrm{l} / \mathrm{s}$, and the efficiency was $72 \%$. Also, the results show that the increase in the number of blades increases the torque and efficiency of the turbine.
\end{abstract}

\section{Introduction}

The continuous and increasing demand for fossil fuels as energy, lead to an imperative to alternative means to meet current and future energy needs, especially as fossil fuels are declining and have disadvantages. The using of fossil fuel increases greenhouse gases as it gives large amounts of Sulfur dioxide and dioxide gases Carbon and Nitrogen oxide. These emissions cause climate changes and cause global warming [1]. In recent years, Iraq has begun to suffer from problems of low river level and the Euphrates and Tigris are expected to decrease by 50\%, 25\% respectively by 2025 [2]. Large power plants placed on dams, including Haditha dam in Anbar province, have been affected by reduced production of generated energy due to the low water level within the Euphrates River, as well as thermal and gas power plants, which require high flows for the operation of cooling systems such as The Zweia station in Anbar province (This type of station (small-generation plants) which is

* Corresponding author.

E-mail address: ammar.kamel@uoanbar.edu.iq

https://doi.org/10.37934/arfmts.80.1.112127 
the subject of our research is one of the most successful solutions that must be studied and developed in Iraq. There is a greater impetus towards the renewable energy sources to increase the global energy produced [3-9]. Hydropower was introduced to be an alternative solution, especially since $71 \%$ of the land is covered with water, this means that an inexpensive and environmentally friendly electrical energy can be generated, and this energy can expand rapidly [10]. One of the technologies that Archimedes screw turbines are fish friendly is because they allow fish to pass through them without damage.

The name Archimedes screw came according to its inventor Archimedes, Archimedes screw was used for the first time for the purpose of irrigation in the Nile Delta where it was It is used to raise water from low areas to higher areas and also can work on wastewater treatment [1]. The main design of Archimedes screw has made it a tool to generate electric energy with high efficiency and also that $80 \%$ of the energy available in high water can be converted to mechanical energy, another advantage of Archimedes, that it is practically cheap, they can be low head less than $10 \mathrm{~m} \mathrm{[11].} \mathrm{The}$ screw can manufacture it from locally available materials, as well as installed, as it is installed in previous stations or Old dams, thus eliminating the cost of civil works. Rorres [12] presented an analytical study to improve the design of the Archimedes screw as a water pump and the cost is to maximize the amount of water that is raised so determine the external and internal parameters of the screw and reach optimal ratios for the parameters where internal parameters are Inner screw radius $(\mathrm{Ri})$, Number of blades $(\mathrm{N})$, and Pitch of one blade $(\mathrm{P})$; External parameters are (Outer screw radius (Ro), length of screw (L), and Slope of screw $(\alpha)$

Screw turbine action system Archimedes, water enters from the top of the screw and due the hydrostatic pressure on the surface of the screw and its continuation down, the screw rotates that is, the kinetic energy of the water turned into a rotational energy of the blades [13]. Müller and Senior [14] developed a theoretical model and compared with the experimental results, was reached to a similar efficiency to the experimental results well, also found that each nail geometry has a higher limit of efficiency, and that the efficiency of the Archimedes screw is indicative of both the geometry of the screw and mechanical losses, in addition to the efficiency increases with the increase in the number of blades and the decrease in the angle of the tilt of the spear with the horizon of the head descending between the blades .

Dellinger et al., [15] presented an experimental and numerical study to predict the performance of a screw turbine, the experimental study was conducted in different flows, the results showed that efficiency is higher than $80 \%$ in a different set of conditions. Numerical study was using CFD Software and when comparing the results, the efficiency was very close, the main objective of the study is to rely on CFD software in developing a methodology for predicting the performance of the Archimedes screw. Saroinsong et al., [16] offered an experimental study to identify the performance of the Archimedes screw turbine under the influence of different flows and a different inclination angle of the shaft, it was found that the maximum power occurred at an inclination angle of shaft $45^{\circ}$, the maximum efficiency was $89 \%$ at the angle of $25^{\circ}$ miles. the study showed that the speed of entry is an important factor in the generation of power and that the Archimedes screw turbine is at the highest performance with low inclination angles of the shaft.

Lubitz [17] have addressed the energy losses in Archimedes screw caused by water leaks between the outer edge of the screw and the trough. Based on experimental equations, the value of the Gap can be determined as in the Nagel equation, but this is an empirical estimate because it is calculated on the basis of diameter only. From theoretical evidence that the lower Gap give the higher of rotational velocity of the screw. 
The purpose of this research is to reach to a good understanding of the working Archimedes screw turbine. The main objective of this research may be listed below

i. Construct an experimental apparatus related to production of energy depending on lowhead turbine principals.

ii. Construct a numerical model of the same Archimedes turbine, using this numerical model to study the performance of such turbines. And study effect the of other parameters

iii. Make a comparison between experimental and numerical study.

iv. Determine the main parameters that effect the performance of Archimedes turbine.

\section{Methodology}

\subsection{Experimental Model}

To develop a certain design for Archimedes screw, it is necessary to have knowledge of some main information about the experimental screw turbine to be manufactured. Therefore, all the parameters that affecting the design and construction of the screw with their limitations should be taken into consideration. The parameters that are taken in the design of the experimental screw will be divided into two main categories as shown in the next sub-sections Figure 1.

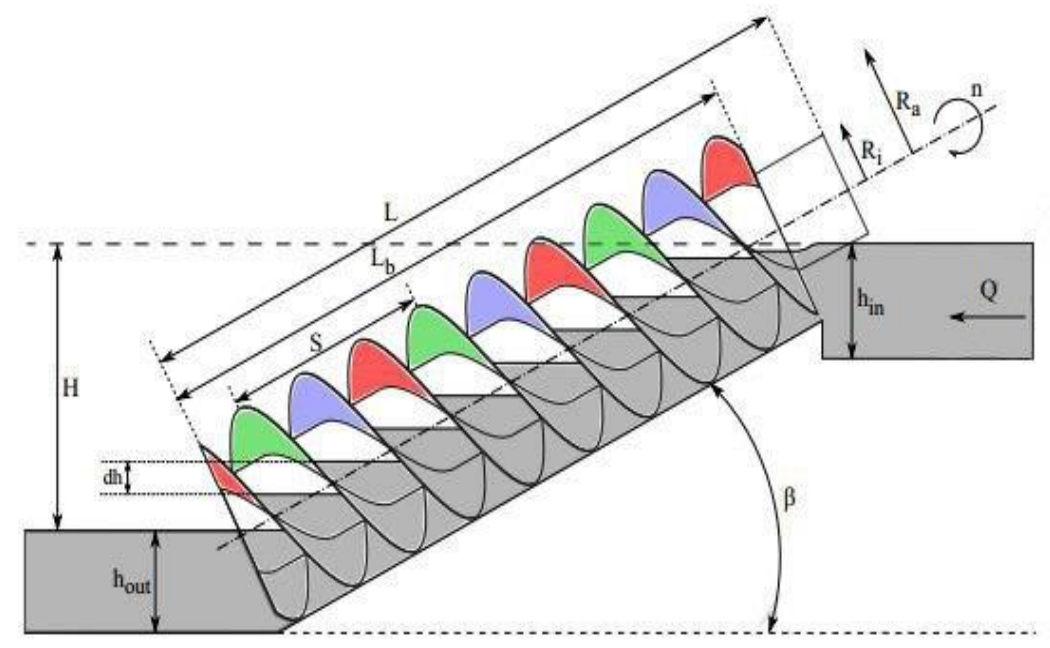

Fig. 1. General principle of Archimedes screw turbine [18]

The experimental rig is manufactured from available materials. This minimizes the cost of the apparatus. The Archimedes screw turbine consists of 12 helix (as in Figure 2) welded on hollow shaft. The shaft and helixes are made of stainless steel (shown in Figure 3). The screw is covered with a small tube made of galvanized iron. The top of which has been cut to work as trough, and the dimensions as shown in the Table 1 


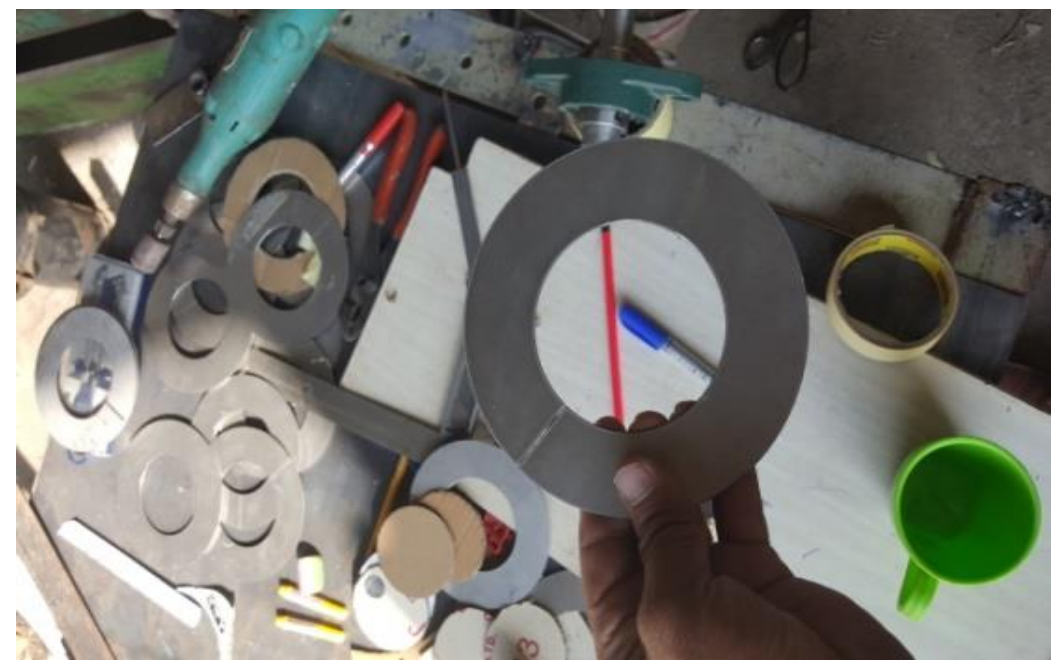

Fig. 2. The helix before welded on shaft

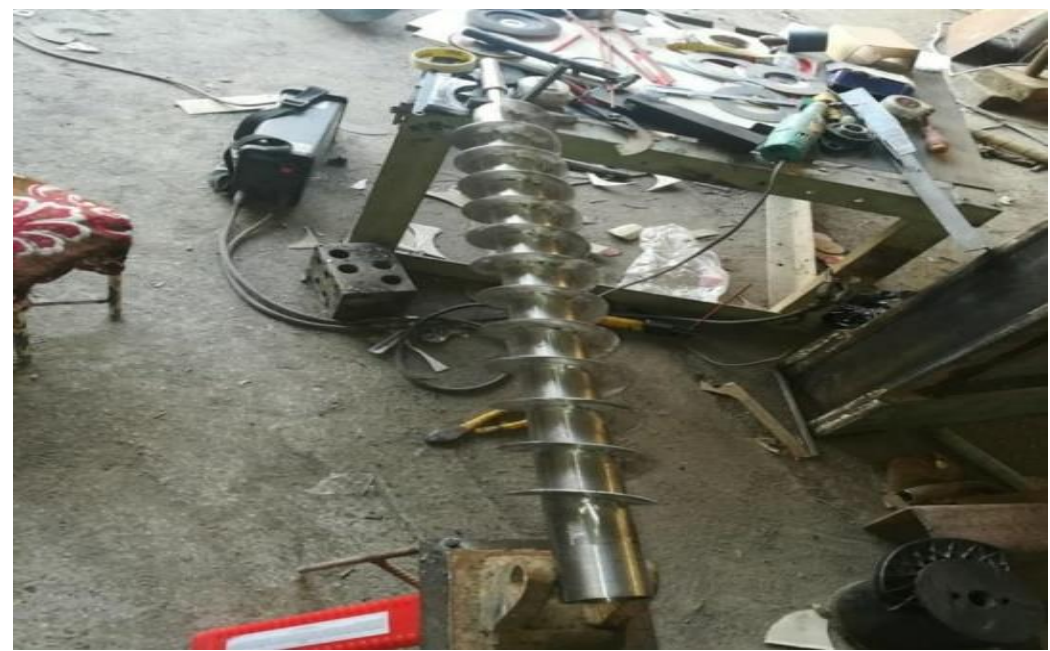

Fig. 3. Shaft with blade

Table 1

Parameters of screw turbine (experimental model)

\begin{tabular}{lll}
\hline Parameters & Variable & Value \\
\hline Screw length & $\mathrm{L}$ & $1000 \mathrm{~mm}$ \\
Outer diameter & $\mathrm{Do}$ & $130 \mathrm{~mm}$ \\
Inlet diameter & $\mathrm{Di}$ & $70 \mathrm{~mm}$ \\
Number of blades & $\mathrm{N}$ & 1 \\
Number of helixes & $\mathrm{m}$ & 12 \\
Pitch & $\mathrm{P}$ & $70 \mathrm{~mm}$ \\
Gap width & $\mathrm{G}_{\mathrm{w}}$ & $2 \mathrm{~mm}$ \\
Trough diameter & $\mathrm{Dt}_{\mathrm{t}}$ & $134 \mathrm{~mm}$ \\
Slope & $\alpha$ & $30^{\circ}, 35^{\circ}, 40^{\circ}, 45$ \\
\hline
\end{tabular}

The Archimedes screw turbine is installing on open channel, as shown in Figure 4 


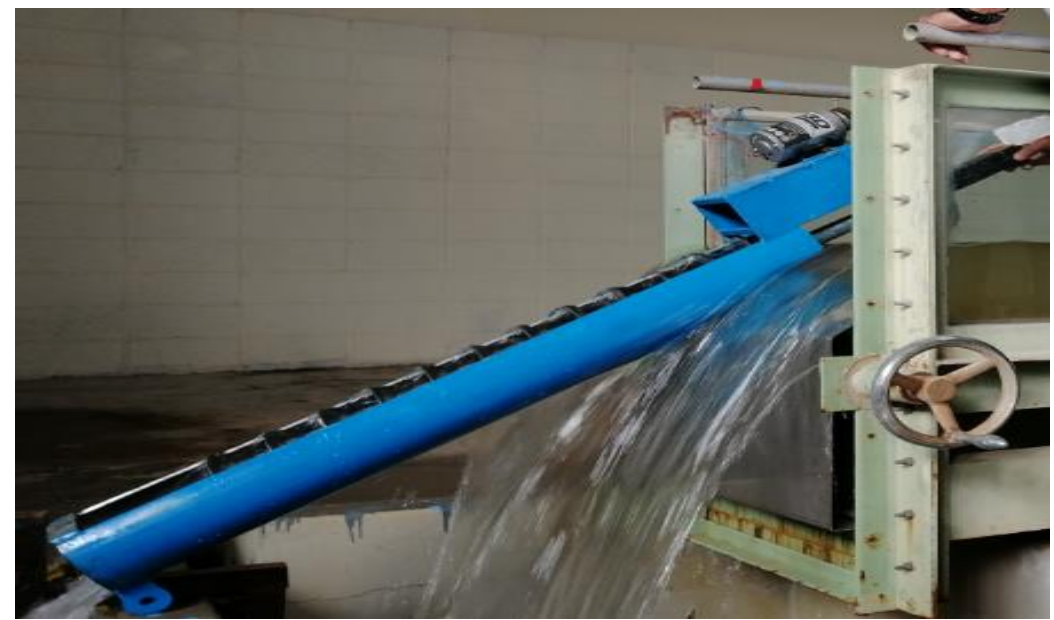

Fig. 4. Archimedes screw after completion of manufacturing

The hydraulic power of the Archimedes screw turbine was calculated using the Eq. (1).

Phyd $=\rho g Q H$

where $\rho$ is water density; $Q$ is flow rate; $g$ is gravitation and $H$ is the head from top to end of blade

Pmec=T. $\omega$

$\omega=(2 \pi n) / 60$

where $\mathrm{n}$ is number of rotations per minute; pmec is mechanical power of screw turbine; $\mathrm{T}$ is torque is equivalent with angular velocity and $\omega$ is angular velocity

Efficiency of screw turbine is calculated by

$\eta=P m e c / P h y d * 100 \%$

In the experiment, the turbine was supplied with water by a hydraulic laboratory channel shown in Figure 5 made of iron. The channel is equipped with water by a pump of $10 \mathrm{hp}$, and there is also a lock to control the flows entering the channel.

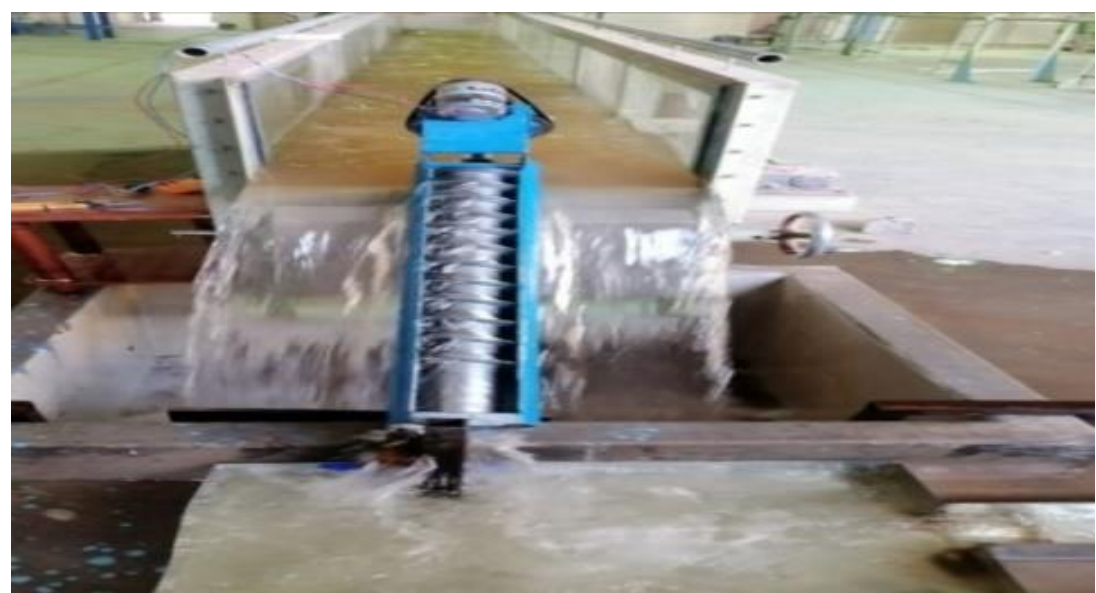

Fig. 5. Archimedes screw with hydraulic channel during operation 


\subsubsection{Uncertainty analysis}

An uncertainty analysis is an important tool in experimental investigations. This can be performed for the instrumentations that be used in the experimental arrangements. For each measured variable, one or more elemental uncertainties can contribute to the total uncertainties for the variable. These elemental uncertainties were combined using the Root Mean Squared (RMS) rate method according to Holaman and Gajda [19] and Khalil et al., [20]. For the measured variables in the different experiments, the results for the elemental uncertainties are showed in Table 2 and Table 3.

Table 2

The Accuracy values of equipments

\begin{tabular}{lll}
\hline Equipment & Resolution & Accuracy \\
\hline Ammeter & $0.01 \mathrm{Amps}$ & $\pm 1.5 \%$ \\
Voltmeter & $0.01 \mathrm{Volts}$ & $\pm 2 \%$ \\
Rotameter & $0.01 \mathrm{~L} / \mathrm{s}$ & $\pm 3 \%$ \\
Tachometer & $0.5 \mathrm{rpm}$ & $\pm 2 \%$ \\
\hline
\end{tabular}

Table 3

The Accuracy values of different variable

\begin{tabular}{ll}
\hline Parameter & Uncertainty \\
\hline Flowrate & $\pm 1.8 \mathrm{m3} / \mathrm{s}$ \\
Rotation of Speed & $\pm 2 \% \mathrm{rpm}$ \\
Torque & $\pm 3.5 \mathrm{~N} \cdot \mathrm{m}$ \\
Power & $\pm 4 \mathrm{Watt}$ \\
\hline
\end{tabular}

\subsection{Numerical Model}

Computational fluid dynamics (CFD) is one of the branches of fluid mechanics that uses numerical methods algorithms to solve and analyze problems involving fluid flows. For complex configurations solution of fluid flow may be achieved numerically in smaller time and cheaper cost compared with experimental work.

\subsubsection{Geometry}

The Archimedes screw model was designed using Solid Works with the same dimensions as the laboratory model (Figure 6).

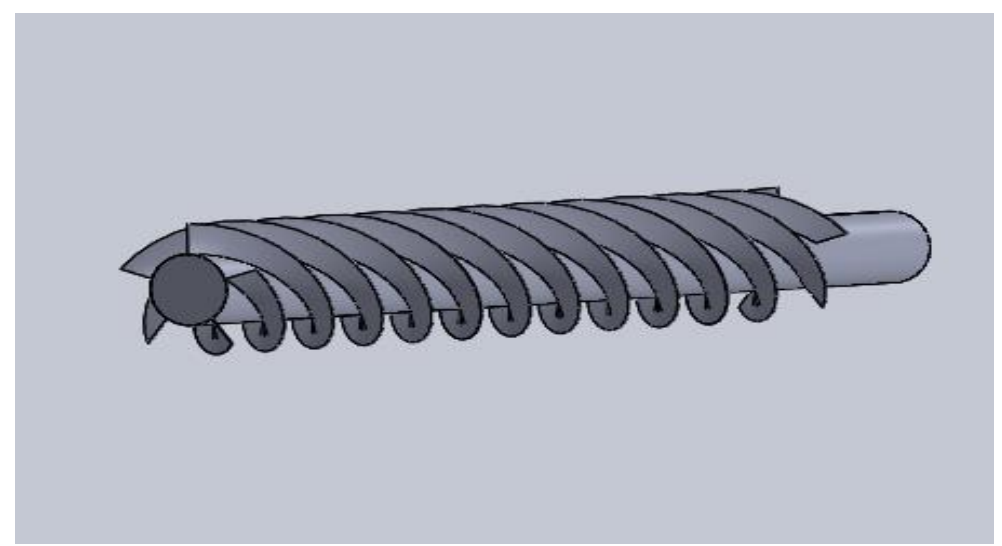

Fig. 6. Bladed screw turbine by solid works 
The simulation of Archimedes screw turbine model was done using ANSYS FLUENT, Computational Fluid Dynamics (CFD). It is a branch of fluid mechanics which is a simulation of fluid flow and heat transmission and some other phenomena. This method is important in industrial applications, and the advantages of this technique is that it reduces the time and cost of design for applications. Overall, the CFD model reduces the effort by $20-40 \%$ compared to the physical model [21], the basis in this technique is the equations of Navier Stock, developed by Claude Louis Navier in the beginning of 1800 [22].

\subsubsection{Governing equations}

The flow of fluid through a control volume can be described by the complete Navier- Stokes equations. These equations can be derived depending on the principle of conservation of mass, momentum, and energy $[23,24]$. In this research, we didn't rely on the energy equation because we didn't take the heat into consideration.

Continuity equation

$\frac{\partial \rho}{\partial \mathrm{t}}+\frac{\partial(\rho \mathrm{u})}{\partial \mathrm{x}}+\frac{\partial(\rho \mathrm{v})}{\partial \mathrm{y}}+\frac{\partial(\rho \mathrm{w})}{\partial \mathrm{z}}=0$

Conservation of momentum

$\mathrm{x}$-momentum equation

$\frac{\partial(\rho \mathrm{u})}{\partial \mathrm{t}}+\frac{\partial\left(\rho \mathrm{u}^{2}\right)}{\partial \mathrm{x}}+\frac{\partial(\rho \mathrm{uv})}{\partial \mathrm{y}}+\frac{\partial(\rho \mathrm{uw})}{\partial \mathrm{z}}=-\frac{\partial \mathrm{p}}{\partial \mathrm{x}}+\frac{1}{\mathrm{Re}}\left[\frac{\partial \tau_{\mathrm{xx}}}{\partial \mathrm{x}}+\frac{\partial \tau_{\mathrm{xy}}}{\partial \mathrm{y}}+\frac{\partial \tau_{\mathrm{xz}}}{\partial \mathrm{z}}\right]$

Y-momentum equation

$\frac{\partial(\rho \mathrm{v})}{\partial \mathrm{t}}+\frac{\partial(\rho \mathrm{uv})}{\partial \mathrm{x}}+\frac{\partial\left(\rho \mathrm{v}^{2}\right)}{\partial \mathrm{y}}+\frac{\partial(\rho \mathrm{vw})}{\partial \mathrm{z}}=-\frac{\partial \mathrm{p}}{\partial \mathrm{y}}+\frac{1}{\mathrm{Re}}\left[\frac{\partial \tau_{\mathrm{xy}}}{\partial \mathrm{x}}+\frac{\partial \tau_{\mathrm{yy}}}{\partial \mathrm{y}}+\frac{\partial \tau_{\mathrm{yz}}}{\partial \mathrm{z}}\right]$

z-momentum equation

$\frac{\partial(\rho w)}{\partial \mathrm{t}}+\frac{\partial(\rho \mathrm{uw})}{\partial \mathrm{x}}+\frac{\partial(\rho \mathrm{vw})}{\partial \mathrm{y}}+\frac{\partial\left(\rho \mathrm{w}^{2}\right)}{\partial \mathrm{z}}=-\frac{\partial \mathrm{p}}{\partial \mathrm{z}}+\frac{1}{\mathrm{Re}}\left[\frac{\partial \tau_{\mathrm{xz}}}{\partial \mathrm{x}}+\frac{\partial \tau_{\mathrm{yz}}}{\partial \mathrm{y}}+\frac{\partial \tau_{\mathrm{zz}}}{\partial \mathrm{z}}\right]$

\subsubsection{Assumptions}

There is a necessary assumption required before applying the conventional Navier- Stokes equation to model the fluid through the Archimedes screw turbine. The major assumptions are the following
i. Fluid (water) is in single phase
ii. Water is considered as incompressible fluid
iii. Properties of water are temperature independent

\subsubsection{Boundary condition}

In this simulation, the transient flow state was used as its Boundary condition. The speed of entry at upstream (inlet) as well as the rotational speed of the screw were taken from the experimental results, while the pressure at downstream (outlet) is equal to 0 (Table 4). 


\section{Table 4}

The values of Reynolds number and velocity

\begin{tabular}{ll}
\hline Name & Type \\
\hline Inlet & Velocity inlet \\
Outlet & Pressure outlet \\
Screw & Rotational speed \\
\hline
\end{tabular}

\subsubsection{Mesh}

A non-uniform grid has been chosen to give a good accuracy as well as the consistency of the numerical results (Figure 7 ). Convergence criteria were set to less than $\left(10^{-6}\right)$ for continuity and momentum residuals. Number of iterations was 100 . Through theoretical study, upon analysis, it was found that the best value for the size of the element is $5 \mathrm{~mm}$, where values greater and less than 5 $\mathrm{mm}$ were tested, the large values from $5 \mathrm{~mm}$ did not give accurate results, but when at small values from $5 \mathrm{~mm}$, the results did not change, just an increase at the time of the analysis. Total number of tetrahedral mesh shape of 673161 elements was used. This number of elements was used after making a set of cases by the number of different elements as shown in Figure 8 . The figure represents the number of elements with torque it was recorded that the values of torque decreased rapidly when the number of elements increased to reach about 511000 elements, from that point started a linear line flat, semi-constant that did not change.

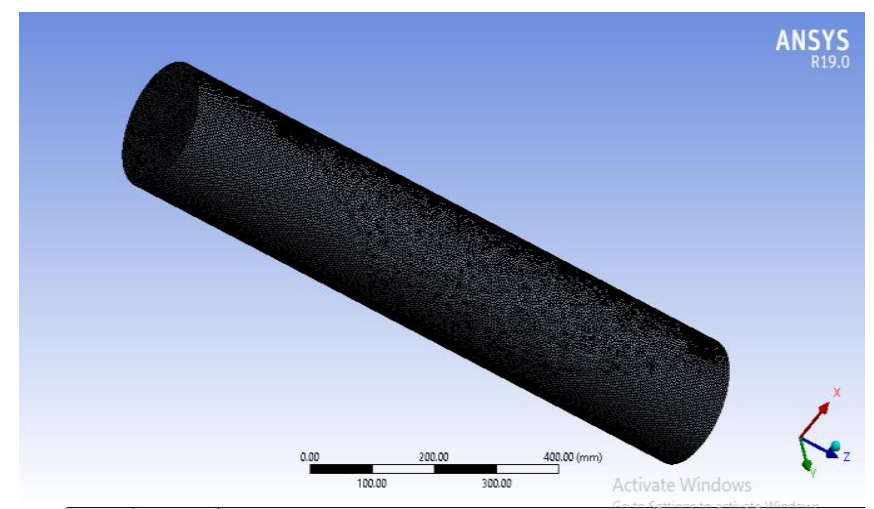

Fig. 7. Mesh model of screw turbine

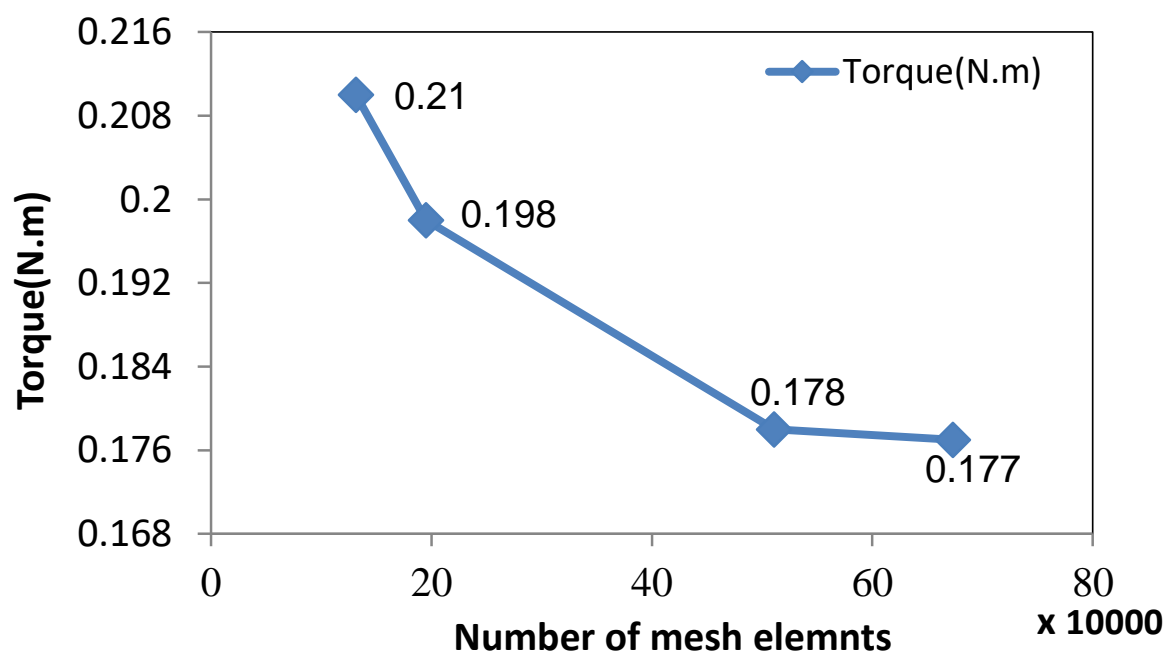

Fig. 8. Mesh model of screw turbine 


\section{Results and Discussion}

Figure 9 shows the relation between mechanical energy with the flow rate at $\alpha=30^{\circ}$. Obviously from this curve the higher the flow rate, the more mechanical energy. That is, the trend line is almost equal. The reason for the increase in mechanical energy is that the flow rate increases the force that affects the blades, and thus the rotation of the blade increases, from which the mechanical energy increases.

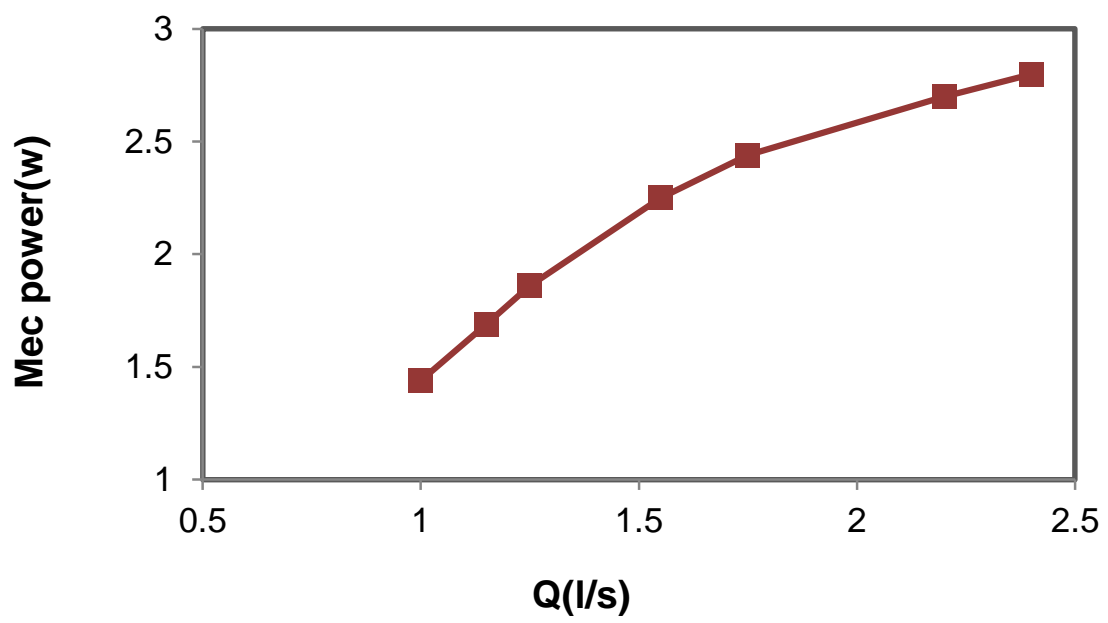

Fig. 9. The relation between flow rate and mechanical power at $\alpha=30^{\circ}$

The relationship between flow and efficiency with an angle of $35^{\circ}$ shows in Figure 10 . When the flow increases, the efficiency of the Archimedes screw increases until it reaches its peak at the optimal flow and then begins to decrease. This means that to obtain a high efficiency the flow must be optimal.

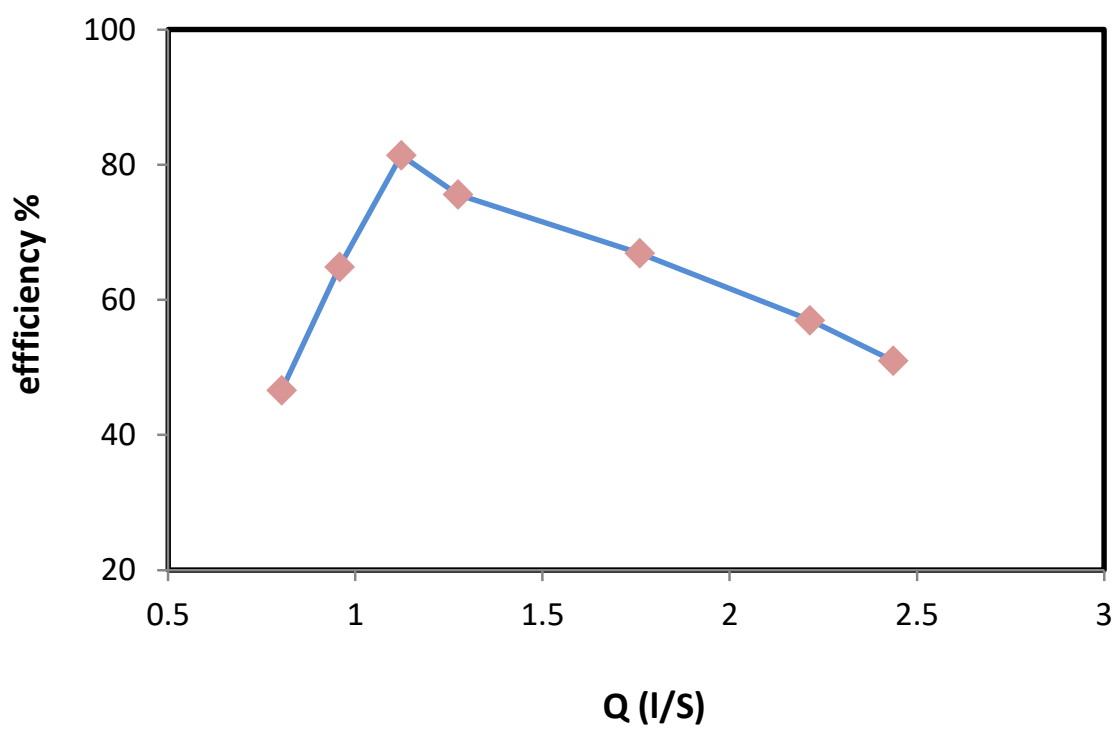

Fig. 10. The relation between efficiency and flow rate at $\alpha=35^{\circ}$ 
From Figure 11 we note that when the flow increases, the rotational speed increases at each angle of inclination, but when the value of the angle increases, the rotational speed lines converge, meaning that the change in rotational speed becomes small and this means that there are losses in energy due to the overflow.

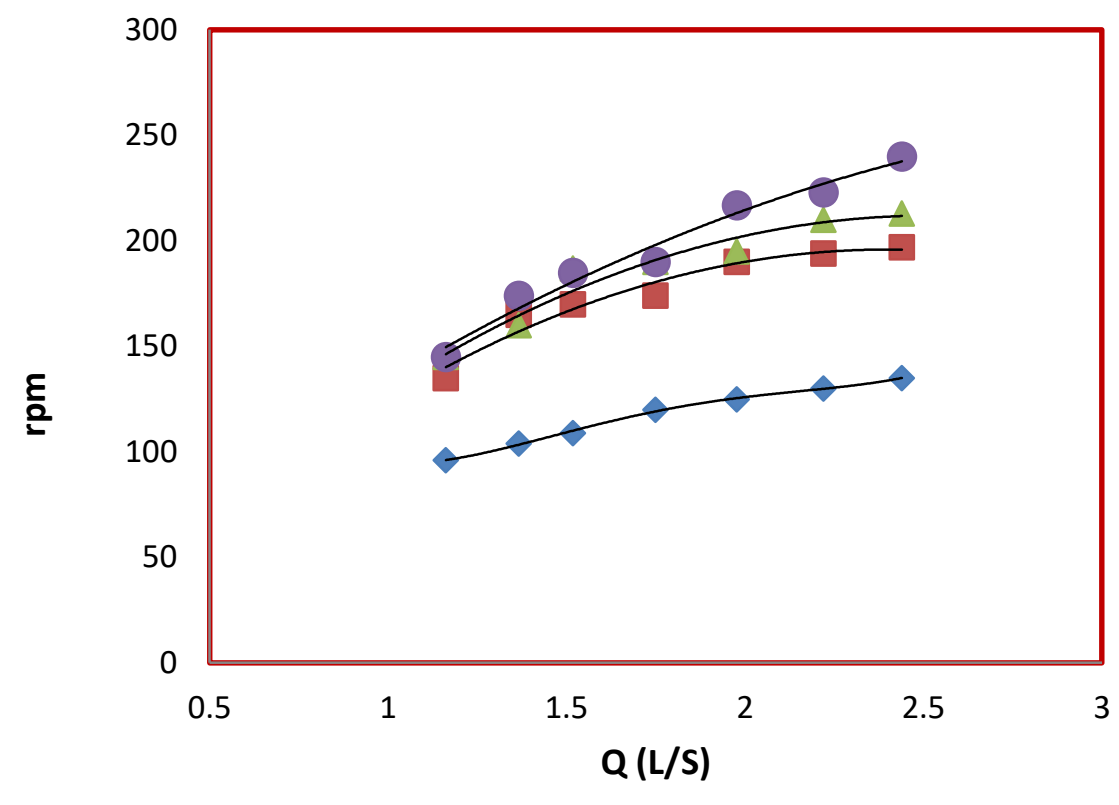

$\checkmark$ Angle $30 \quad$ Angle $35 \quad$ Angle $40 \quad$ Angle 45

Fig. 11. Relation between rotation and flow rate with number of angles

Figure 12 Shows the relationship between efficiency and rotation at angle $35^{\circ}$, we notice that efficiency in the beginning increases with increasing rotational speed until it reaches the top at the highest value of $81.4 \%$ at a rotation of 165 , which is the highest value of efficiency reached in the practical test, after which efficiency begins Decreasing with increasing rotation. From the results it was concluded that the optimum angle is $35^{\circ}$.

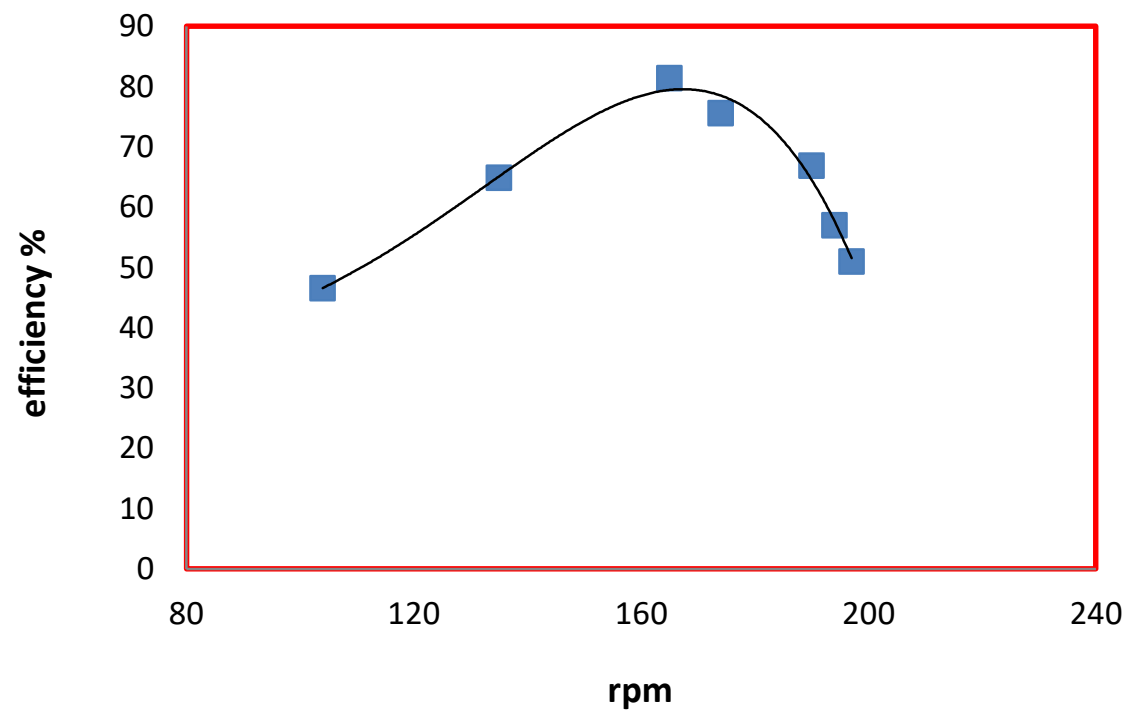

Fig. 12. The relation between efficiency and rotation ( $35^{\circ}$ Angle) 
The relationship between the torque of Archimedes screw and the number of blades at $\alpha=35^{\circ}$ shows in Figure 13, the greater the number of blades lead to the greater the torque due to the greater increase in the area of water contact with the blades, but with the continuous increase in the blades, the difference between the torque values becomes little, therefore the optimum number of blades can be chosen because the greater the number of blades the manufacturing process becomes more complicated and also expensive.

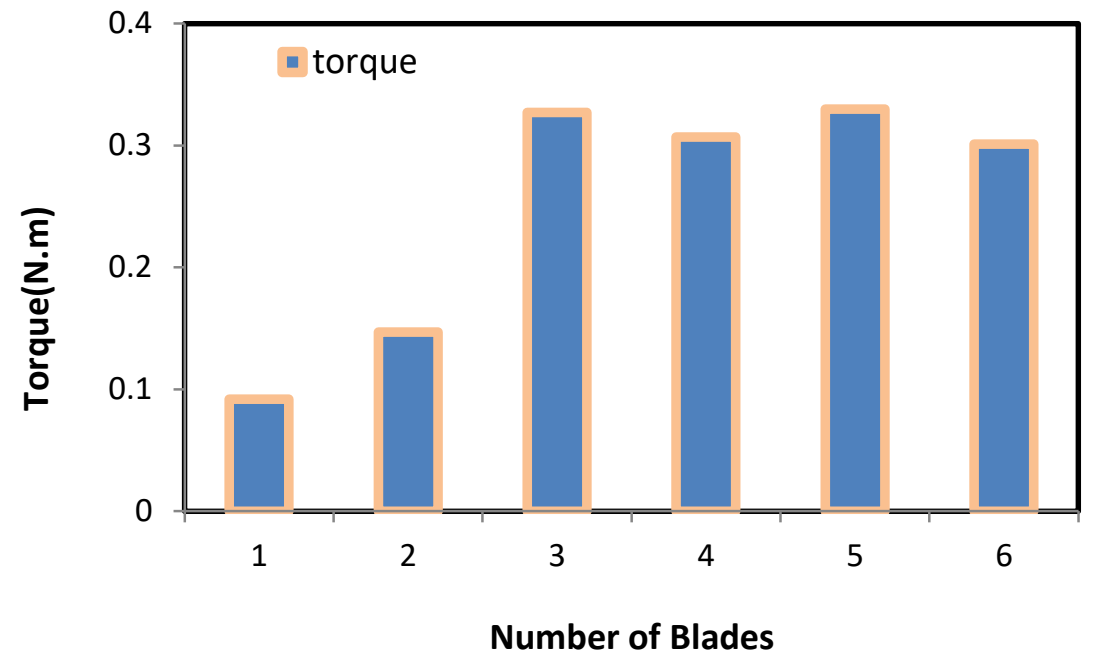

Fig. 13. Torque with Number of Blades at $\alpha=35^{\circ}$

Figure 14 shows the relationship between efficiency and the number of blades for an Archimedes screw turbine at $\alpha=35^{\circ}$. From figure, we can be note that the higher the number of blades for the Archimedes screw, the greater the efficiency, and this is due to the greater the number of blades, the higher the surface area of contact with the water entering its energy, and thus increase the torque. We note that the increase in efficiency becomes little or wobbly when the continuous increase in the number of blades.

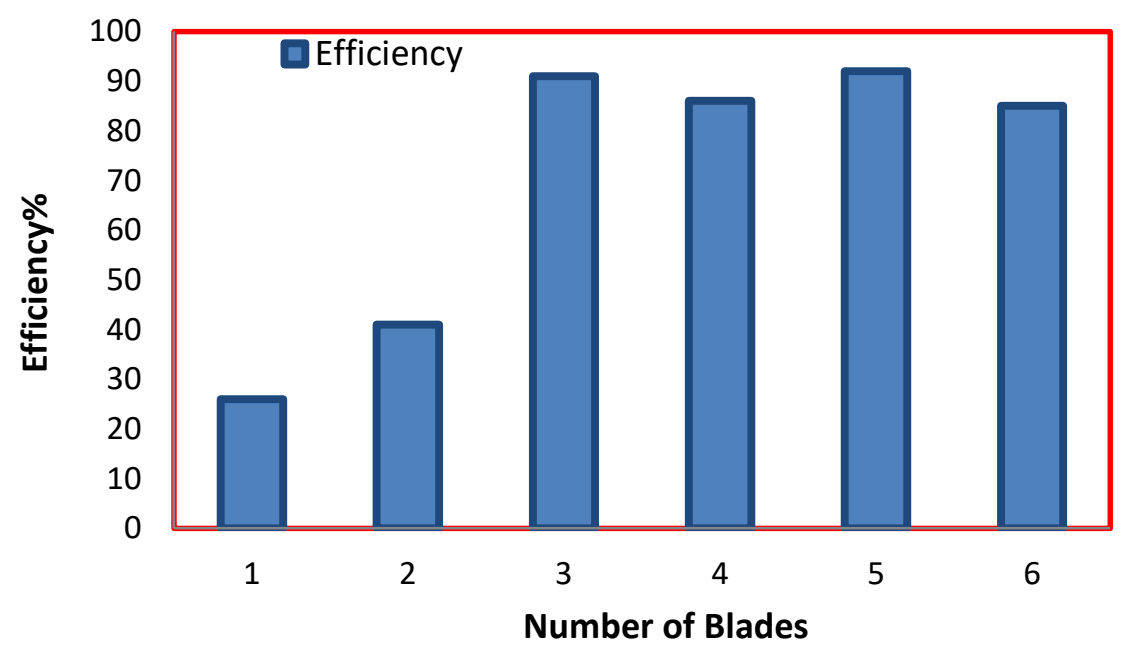

Fig. 14. Efficiency with Number of Blades at $\alpha=35^{\circ}$ 


\subsection{Validation of Results}

The numerical results of the physical model are validated with experimental results. Figure 15 shows that both results are closer to each other to a good extend. The deviation between them is less than $5 \%$. After obtaining the experimental results, the results were calibrated by using the CFD at a $30^{\circ}$ angle. The results In Figure 15 showed that there is a match for the mechanical energy values with respect to the rotational movement between the experimental results and the numerical results at the angles with the lowest inclination, but at the large angles also there is a match but with a lower flow of the CFD since the losses are neglected That is, the analysis was based on the adoption of the ideal situation and this confirms that energy losses at large angles and high flows, that is, above the absorptive capacity.

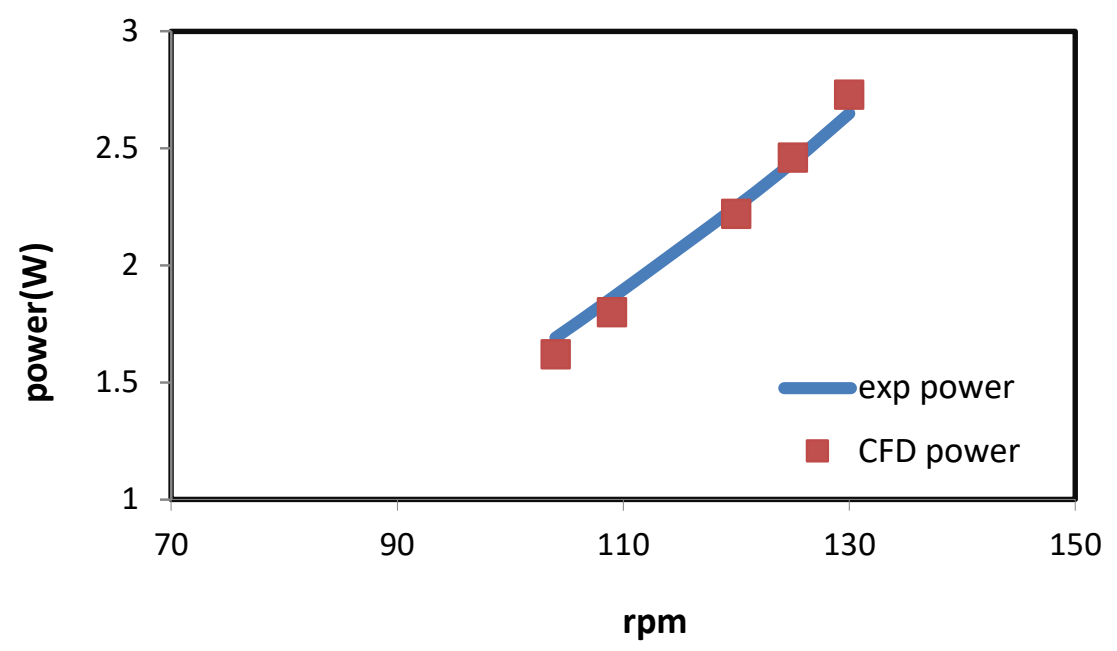

Fig. 15. The relation between power and rotation for experimental and numerical examination $\left(30^{\circ}\right.$ angle)

To verify the physical model presented in present study and the results obtained from this model, the results of the laboratory work were compared with the experimental results obtained by Yulistiyanto [25] the results of mechanical energy with flow, the model was composed of the following parameters $L=1000 \mathrm{~mm}, R o=142 \mathrm{~mm}, \mathrm{Ri}=76.2 \mathrm{~mm}$, despite the different dimensions of the two processes as well as the inflows. The energy in both models increases as flows increase and with similar behavior, and this is illustrated in Figure 16 and Figure 17.

Simulation of the flow of water shown in the Figure 18. It shows the velocity streamline of Archimedes screw turbine, the velocity at the beginning of the entrance is low and smooth because it is not affected by the movement of the blades and Then the speed begins to increase with the movement down to the end of the blades and then decreases towards the outlet.

In the Figure 19 we observe the change of pressure along the Archimedes screw. This change in pressure occurs due to the effect of the flow of water entering the turbine as the highest pressure occurs at the beginning of entry due to large collisions on the blades and then the pressure decreases. 


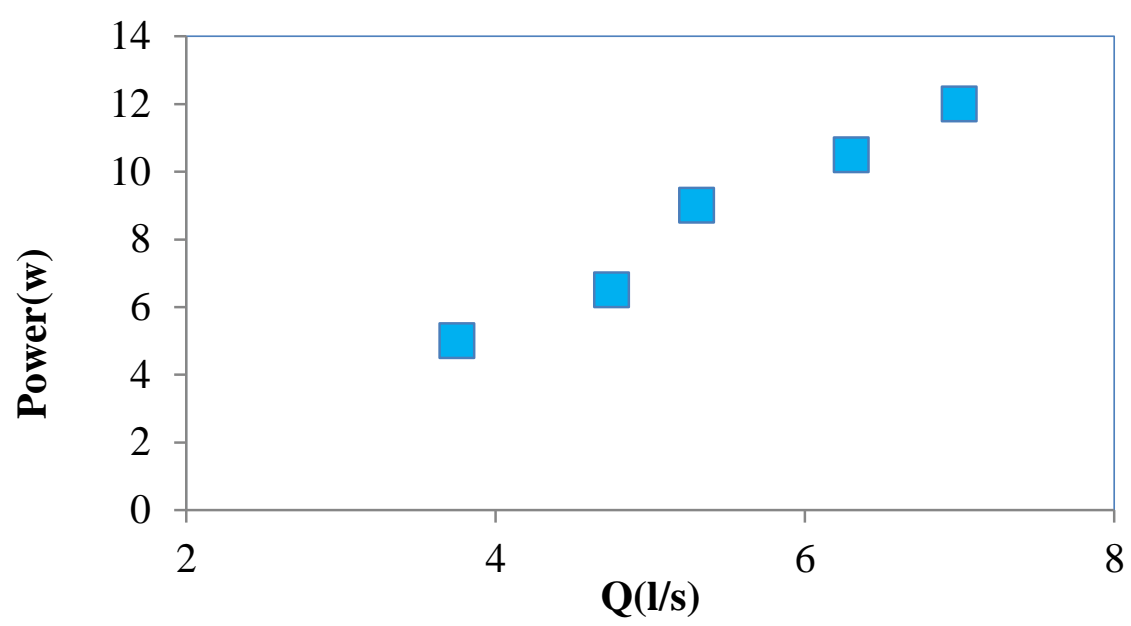

Fig. 16. Power with flow rate of Bambang Yulistiyanto [25], L=1000mm, $\mathrm{Ro}=142 \mathrm{~mm}, \mathrm{Ri}=76.2 \mathrm{~m}$

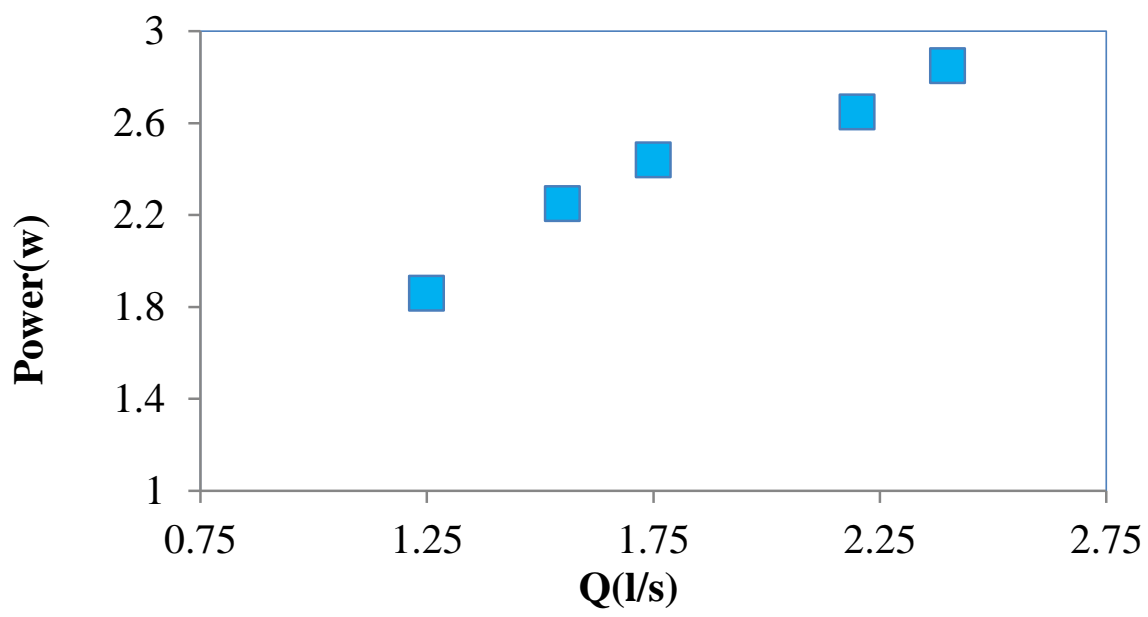

Fig. 17. Power with flow rate of experimental model

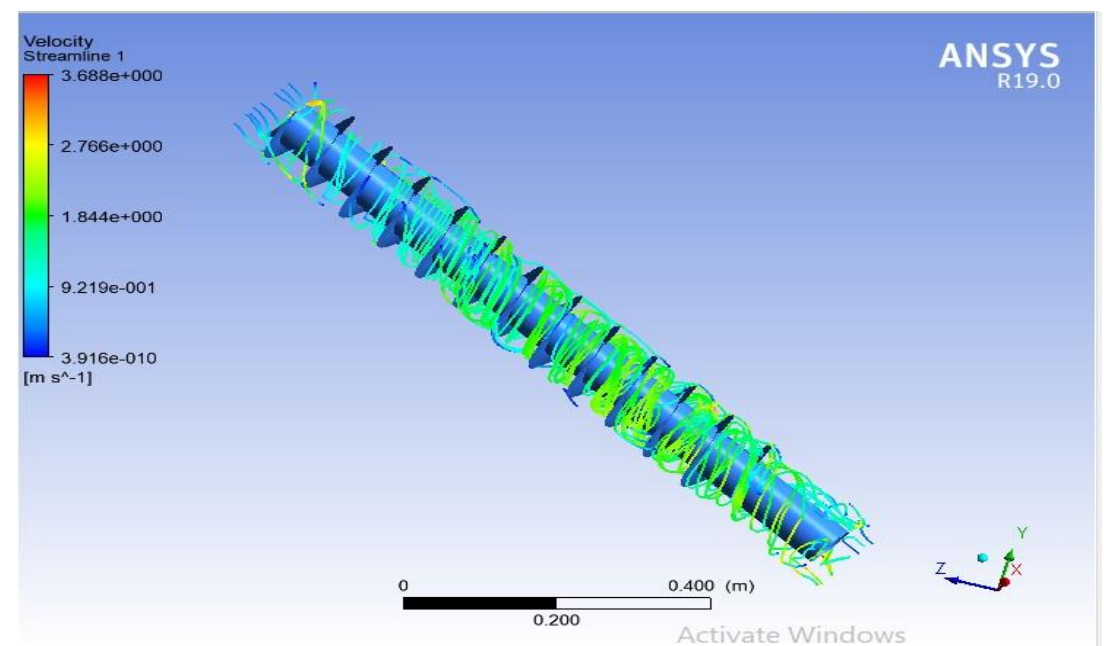

Fig. 18. Simulation of flow water (velocity streamline) 


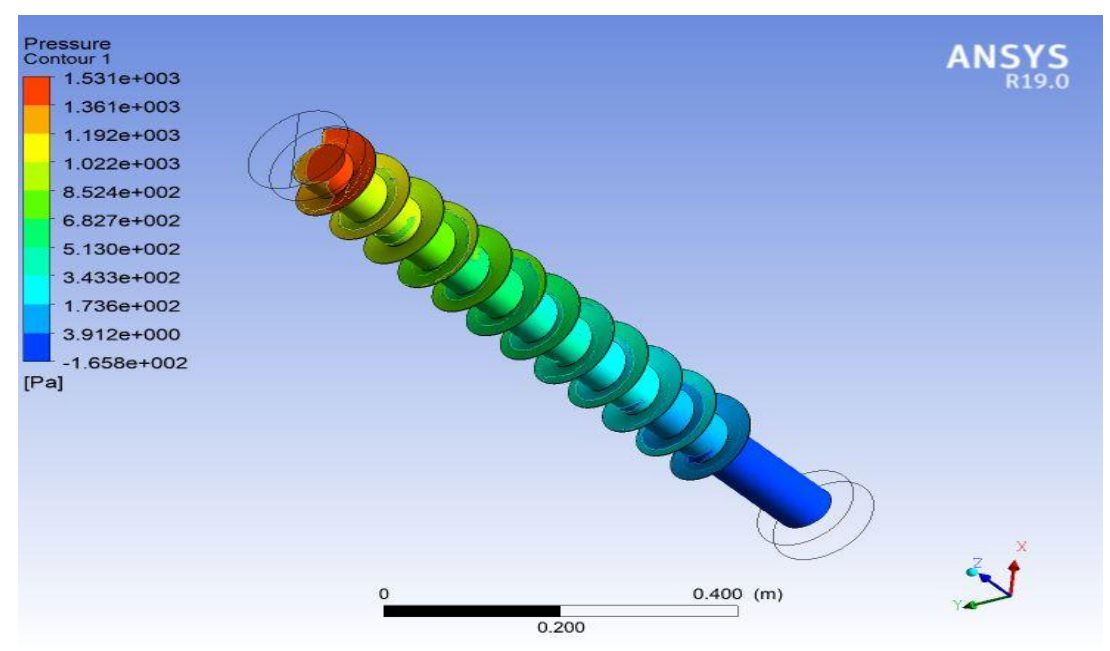

Fig. 19. Simulation of flow water (pressure)

\section{Conclusion}

In this research, an Archimedes screw turbine was studied using the practical method and the numerical method using the Ansys Fluent software (Computational Fluid Dynamics) CFD and the study was done by changing some parameters such as the angle of inclination of the screw and the flow and the number of blades and the results were obtained depending on those different conditions.

Through the results, we note that the direct proportion between the flow and the mechanical energy, the increased flow increases the mechanical energy, but in relation to the efficiency, it is not necessarily that it increases, as we noticed from the efficiency and flow curve that the efficiency increases to a point where its highest value reached $81.4 \%$, and then begins to decrease and the reason It is due to the flow being higher than normal or above the screw susceptibility, so the increase is overflow.

If the case of flow changes with changing angles $30,35,40,45$, we find that when the flow increases, the rotational speed increases with each angle of the slope of the column, but when you continue to raise the value of the angles, the lines of rotation relationship converge with the flow and this indicates that there is no Need to increase the value of the angle because it gives the same value of rotation and the same energy with greater losses, from the results show that the maximum angle is 35 degrees because it gave the highest efficiency with high energy as the efficiency reached $81.4 \%$, and the energy is 4.26 watts.

When the discharge increases, the rotational speed increases, but the efficiency increases until it reaches its highest value at $81.4 \%$ at an angle of 35 and then begins to decrease after reaching above the optimal flow, where the losses begin due to the overflow.

In the case of torque and efficiency with the number of blades, the number of torque and efficiency both of them increase with the increase in the number of blades due to the increase in the surface area of contact between water and the blades, but with the continued increase in the number of blades there was a convergence of the values of torque and efficiency, meaning that there is no need for Increasing the number of blades because the torque and the efficiency are the same, and also increasing the number of blades means difficulty in manufacturing and an increase in cost. 


\section{References}

[1] Rosly, Zafirah, Ummu K. Jamaludin, N. Suraya Azahari, M. Ammar Nik Mu'tasim, A. Nurye Oumer, and N. T. Rao. "Parametric study on efficiency of archimedes screw turbine." ARPN Journal of Engineering and Applied Sciences 11, no. 18 (2016).

[2] Alwash, A., H. Istepanian, R. Tollast, and Z. Al-Shibaany. "Towards Sustainable Water Resources Management in Iraq." Iraq Energy Institute: London, UK (2018).

[3] Abed, Azher M., Doaa Fadhil Kareem, Hasan Sh Majdi, and Ammar Abdulkadhim. "Experimental and CFD Analysis of Two-Phase Forced Convection Flow in Channels of Various Rib Shapes." Journal of Advanced Research in Fluid Mechanics and Thermal Sciences 77, no. 1 (2020): 36-50. https://doi.org/10.37934/arfmts.77.1.3650

[4] Ajeel, Raheem Kadhim, Wan Saiful-Islam Wan Salim, and Khalid Hasnan. "Heat transfer enhancement in semicircle corrugated channel: effect of geometrical parameters and nanofluid." Journal of Advanced Research in Fluid Mechanics and Thermal Sciences 53 (2019): 82-94.

[5] Ajeel, Raheem Kadhim, W. I. Salim, and Khalid Hasnan. "Impacts of corrugation profiles on the flow and heat transfer characteristics in trapezoidal corrugated channel using nanofluids." Journal of Advanced Research in Fluid Mechanics and Thermal Sciences 49, no. 2 (2018): 170-179.

[6] Khan, Ansab Azam, Suliadi Firdaus Sufahani, Khairy Zaimi, and Mohammad Ferdows. "MHD Flow and Heat Transfer of Double Stratified Micropolar Fluid over a Vertical Permeable Shrinking/Stretching Sheet with Chemical Reaction and Heat Source." Journal of Advanced Research in Applied Sciences and Engineering Technology 21, no. 1 (2020): 1-14.

[7] Adam, Nor Mariah, Osam Hassan Attia, Ali Omran Al-Sulttani, Hussein Adel Mahmood, Azizan As'arry, and Khairil Anas Md Rezali. "Numerical Analysis for Solar Panel Subjected with an External Force to Overcome Adhesive Force in Desert Areas." CFD Letters 12, no. 9 (2020): 60-75. https://doi.org/10.37934/cfdl.12.9.6075

[8] Salleh, Hamidon, Amir Khalid, Syabillah Sulaiman, Bukhari Manshoor, Izzuddin Zaman, Shahrin Hisham Amirnordin, Amirul Asyraf, and Wahid Razzaly. "Effects of Fluid Flow Characteristics and Heat Transfer of Integrated Impingement Cooling Structure for Micro Gas Turbine." CFD Letters 12, no. 9 (2020): 104-115.

https://doi.org/10.37934/cfdl.12.9.104115

[9] Saengsikhiao, Piyanut, Juntakan Taweekun, Kittinan Maliwan, Somchai Sae-ung, and Thanansak Theppaya. "Improving Energy Efficiency in the Supermarket by Retrofitting Low E Glass Doors for Open Refrigerated." Journal of Advanced Research in Applied Sciences and Engineering Technology 20, no. 1 (2020): 11-17.

[10] Suraya, A. Nurul, N. M. M. Ammar, and J. Ummu Kulthum. "The effect of substantive parameters on the efficiency of Archimedes screw microhydro power: a review." In IOP Conference Series: Materials Science and Engineering, vol. 100, no. 1, p. 012030. IOP Publishing, 2015. https://doi.org/10.1088/1757-899X/100/1/012030

[11] Maulana, Muhammad Ilham, and Geralg Shelmo Putra. "Performance of Single Screw Archimedes Turbine Using Transmission." In IOP Conference Series: Materials Science and Engineering, vol. 536, no. 1, p. $012022.10 P$ Publishing, 2019.

https://doi.org/10.1088/1757-899X/536/1/012022

[12] Rorres, Chris. "The turn of the screw: Optimal design of an Archimedes screw." Journal of hydraulic engineering 126, no. 1 (2000): 72-80.

https://doi.org/10.1061/(ASCE)0733-9429(2000)126:1(72)

[13] Nuramal, Agus, Putra Bismantolo, Abhijit Date, Aliakbar Akbarzadeh, Afdhal Kurniawan Mainil, and Ahmad Fauzan Suryono. "Experimental study of screw turbine performance based on different angle of inclination." Energy Procedia 110 (2017): 8-13.

https://doi.org/10.1016/j.egypro.2017.03.094

[14] Müller, Gerald, and James Senior. "Simplified theory of Archimedean screws." Journal of Hydraulic Research 47, no. 5 (2009): 666-669. https://doi.org/10.3826/ihr.2009.3475

[15] Dellinger, G., P. A. Garambois, M. Dufresne, A. Terfous, J. Vazquez, and A. Ghenaim. "Numerical and experimental study of an Archimedean Screw Generator." In IOP Conference Series: Earth and Environmental Science, vol. 49, no. 10, p. 102002. IOP Publishing, 2016.

https://doi.org/10.1088/1755-1315/49/10/102002

[16] Saroinsong, Tineke, Rudy Soenoko, Slamet Wahyudi, and Mega N. Sasongko. "Performance of three-bladed Archimedes screw turbine." ARPN Journal of Engineering and Applied Science 11, no. 15 (2016): 9491-9495.

[17] Lubitz, Willam David. "Gap flow in archimedes screws." In CSME Intl. Congress, Toronto. 2014. 
[18] Dellinger, Guilhem, Pierre-André Garambois, Nicolas Dellinger, Matthieu Dufresne, Abdelali Terfous, Jose Vazquez, and Abdellah Ghenaim. "Computational fluid dynamics modeling for the design of Archimedes Screw Generator." Renewable Energy 118 (2018): 847-857.

https://doi.org/10.1016/j.renene.2017.10.093

[19] Holaman, J.P. and Gajda, W.J. (2001) Experimental Method for Engineers. McGrawHill, New York.

[20] Khalil, Wissam Hashim, Zain Alabdeen Hussein Obaid, and H. K. Dawood. "Exergy analysis of single-flow solar air collectors with different configurations of absorber plates." Heat Transfer-Asian Research 48, no. 8 (2019): 36003616.

https://doi.org/10.1002/htj.21558

[21] Linfield, Kevin W., and Robert G. Mudry. "Pros and cons of CFD and physical flow modeling." Airflow Sciences Corporation: Livonia, MI, USA (2008).

[22] Simmons, Scott. "A computational fluid dynamic analysis of Archimedes screw generators." PhD diss., 2018.

[23] Dellinger, Guilhem, Pierre-André Garambois, Nicolas Dellinger, Matthieu Dufresne, Abdelali Terfous, Jose Vazquez, and Abdellah Ghenaim. "Computational fluid dynamics modeling for the design of Archimedes Screw Generator." Renewable Energy 118 (2018): 847-857.

https://doi.org/10.1016/i.renene.2017.10.093

[24] Zuber, Mohammad, Adithya Ramesh, and Darpan Bansal. "The Tesla Turbine-A Comprehensive Review." Journal of Advanced Research in Fluid Mechanics and Thermal Sciences 62, no. 1 (2019): 122-137.

[25] Yulistiyanto, Bambang, Yul Hizhar, and Lisdiyanti Lisdiyanti. "Effect Of Flow Discharge And Shaft Slope Of Archimides (Screw) Turbin On The Micro-Hydro Power Plant." (2012). 